\title{
Transformaciones comunicativas en el consumo del tráiler cinematográfico en internet
}

Javier Lozano Delmar | jldelmar@us.es

UNIVERSIDAD DE SEVILLA

Resumen: El tráiler es una forma breve publicitaria cuya función principal es anunciar una película. A día de hoy, existen muy pocas invesigaciones académicas dedicadas al estudio del tráiler. El objetivo de este trabajo es estudiar cómo afecta la aparición y desarrollo de internet en la construcción de esta forma publicitaria, analizando especialmente la forma en la que el receptor se aproxima a su consumo (cómo, cuándo y dónde) y qué estrategias comunicativas intervienen en el proceso.

Palabras clave: tráiler, publicidad, internet, prosumidor.

Abstract: A trailer is a brief form of advertisement with the only function of promoting a film. Nowadays, there are very few scholar works dedicated to the study of the trailer. The goal of this paper is to study how the development of internet has affected the construction of this form of advertisement, analyzing specifically the way that the audience consumes it (how, when and where) and what communicative strategies are involved in the process.

Key words: trailer, advertising, internet, prosumer. 


\section{Introducción}

Desde los años setenta se produce una expansión y diversificación de soportes audiovisuales. En consecuencia, el proceso de consumo de imágenes se traslada a diversos medios electrónicos como la television, el vídeo o el ordenador, pasando por toda una serie de pantallas: desde las de celuloide a las electrónicas, desde internet a la telefonía móvil, medios interactivos etc. (Amorós y Fontán, 2010). Esta multiplicación de pantallas y de soportes de reproducción ha afectado al consumo de mensajes publicitarios. Hoy en día, en una sociedad cada vez más tecnológica, la industria publicitaria debe saber adaptarse rápidamente a los nuevos medios, teniendo en cuenta las diferentes estrategias comunicativas que plantea cada nuevo soporte $y$, sobre todo, construyendo mensajes publicitarios atractivos, originales y eficaces.

El objeto de este trabajo es estudiar cómo afecta la aparición y desarrollo de internet en la construcción de un formato publicitario específico: el tráiler cinematográfico. Debido a que el tráiler es una de las formas publicitarias con menor atención académica (sobre todo, en comparación con el espot publicitario, el cartel de cine o el videoclip), la realización de esta investigación tiene un triple objetivo. En primer lugar, analizar la evolución del tráiler a través de su adaptación a internet. A este respecto, conviene precisar que, pese a que existen varios trabajos que estudian el desarrollo histórico del tráiler (Kernan, 2004; Hediger, 2002; Johnston, 2009; o el documental Coming attractions. The history of movie trailers del año 2006), analizando la influencia de la televisión o los cambios introducidos con la aparición del vídeo doméstico, las nuevas formas de tráilers que están surgiendo como resultado de la expansión de internet han sido escasamente abordadas. En segundo lugar, analizar la forma en la que el receptor se aproxima al consumo del tráiler (prestando especial atención al cómo, cuándo y dónde) y qué estrategias comunicativas intervienen en el proceso. Por último, este estudio pretende servir como punto de partida para futuras investigaciones que versen sobre el estudio de la forma publicitaria del tráiler, de tal modo que pueda constituirse un campo de estudio más amplio y preciso ${ }^{1}$.

\section{La aparición de Internet. Cambio de paradigma en el consumo de tráilers.}

Con la introducción y expansión de internet como nuevo medio de comunicación, las productoras cinematográficas comienzan a preocuparse por nuevas estrategias y herramientas publicitarias online. En un primer momento, la web promocional es el epicentro de la campaña publicitaria. Se trata de una fuente de información básica acerca de la película que permite dar a conocer el nuevo filme al espectador y aumentar su deseo por asistir al cine (Zufryden, 2000: 55).

\footnotetext{
1 Este artículo recoge una parte de la investigación de la tesis doctoral "Contextualización y
} conceptualización del tráiler" (2012), realizada en la Universidad de Sevilla por Javier Lozano. 
En la actualidad, los tráilers no se distribuyen únicamente a través de la web oficial sino que pueden encontrarse, también, en otros sitios: portales de vídeo (YouTube, DailyMotion, ...), webs especificas donde se ofrecen los tráilers más actuales (Apple Movie Trailers, Trailer Addict), páginas o blogs dedicados a noticias sobre el cine (Blog de Cine, ComingSoon.net, www.aintitcool.com), bases de datos cinematográficas (IMDB, TCM movie database) e, incluso, periódicos online. Además de esto, y como se verá más adelante, los tráilers se comparten en la mayoría de redes sociales (Facebook, Twitter, MySpace, Delicious...). De acuerdo con Doug Hirsch de Yahoo!Movies: "A partir de un determinado momento, los estudios pasaron de apenas preocuparse si sus tráilers se veían en internet a inquietarse terriblemente en caso de que éstos no puedan encontrarse en la red de redes" (Hayes y Bing, 2004 / TdA ${ }^{2}$ ).

La aparición de internet ha modificado el modo en que el espectador visiona y consume tráilers. Como explica Johnston: "la aparición de los tráilers en [...] internet ha modificado la audiencia del tráiler de espectadores masivos a participantes individuales; de espectador pasivo a controlador activo" (2008: 146 / TdA). La movilidad que introdujo el vídeo doméstico se extiende e incrementa gracias al nuevo medio. Ahora los tráilers pueden almacenarse digitalmente en el ordenador personal del espectador o en un disco duro portátil y se encuentran siempre disponibles desde cualquier ordenador con acceso a la red (2008: 148). Además, con la aparición de los reproductores de música móviles como el iPod, la expansión de los Smartphones (iPhone, Samsung Galaxy, Google Nexus One) y la llegada de los tablets (iPad, Samsung Galaxy Tab), el espectador puede acceder al tráiler desde un dispositivo diferente al de su ordenador personal y desde cualquier lugar con una conexión 3G. De este modo, el nuevo medio otorga al espectador, por primera vez, el control sobre qué tráiler ver o descargar de la web (Johnston, 2009: 143).

Como se verá a continuación, la aparición y desarrollo de internet introduce cuatro novedades en el consumo de tráilers. En primer lugar, el tráiler deja de ser algo intrusivo y el espectador decide cuándo y dónde consumirlo. En segundo, con el auge de la web 2.0, el espectador controla la distribución del tráiler. En tercer lugar, el tráiler se transforma en un microsite por el que el espectador puede navegar libremente. $Y$, en cuarto, el espectador se convierte en el propio creador del tráiler.

\subsection{El espectador controla el acceso al tráiler}

Internet ha revolucionado el proceso de comunicación publicitaria. En lo que respecta a la promoción cinematográfica, la mayoría de contenidos publicitarios de la película se encuentran en la red y están disponibles para que el espectador pueda verlos o descargarlos en cualquier momento:

\footnotetext{
2 Traducción del Autor (TdA).
} 
Internet supone, sin duda alguna, una importante ventana de comunicación entre la industria del entretenimiento y el espectador que, desde el sofá de su casa y con tan sólo una red wi-fi, tiene acceso a toda la información que desee sobre su película [...]. Así, mientras que el clásico anuncio o tráiler televisivo[...] pretende atraer espectadores mediante un mensaje intrusivo introducido en mitad de la programación, la gran ventaja del contenido publicitario distribuido en internet es que es el propio espectador quien decide acceder por sí mismo a la información. Gracias a esta ventaja, se pueden desarrollar estrategias comunicativas mucho más concretas y dirigidas, específicamente, al público potencial de la película (Lozano y Hermida, 2010: 15).

Así pues, el nuevo medio otorga, por primera vez, al espectador el control sobre qué tráiler ver o descargar de la web (Johnston, 2009: 143). Esto marca una diferencia con respecto a la aparición del vídeo doméstico. Con el vídeo, el acceso al tráiler se consigue a partir de la adquisición de una película. La película es, por tanto, el objeto principal de búsqueda y no el tráiler. Internet permite, por vez primera, la búsqueda independiente y exclusiva de tráilers: "Una dimensión activa de búsqueda precede la conexión [...] El acceso a la información es voluntaria [...] y el tráiler adquiere un significado diferente porque se busca en lugar de recibirse" (CNC, 2000: 98 y 99 / TdA). En otras palabras, el espectador tiene acceso gratuito e instantáneo a cualquier tráiler que se encuentre alojado en internet.

El tráiler se transforma, de este modo, en un "formato publicitario on-demand [...] El propio consumidor es la figura activa que busca y decide ver el tráiler" (Lozano, 2009: 74). Desde el momento en que se permite al espectador acceder al tráiler dónde y cuándo quiera, se asiste a una revitalización del interés por este y comienza a ganar importancia frente al resto de materiales promocionales (Johnston, 2009: 135-136). Gracias a internet el tráiler se convierte en un producto más, en una mercancía igual de interesante que la película, y su estreno online representa una oportunidad única para el espectador de entrar en contacto con su filme favorito.

Uno de los primeros casos en los que se descubre el potencial del tráiler online es durante la campaña promocional de Star Wars: Episodio I. La amenaza fantasma (Star Wars: Episode I - The Phantom Menace, Lucas, 1999). Lucasfilm decide lanzar el tráiler de la película en internet a través de la web Apple Movie Trailers ${ }^{3}$ :

El 17 de noviembre de 1998 la única forma de ver el primer teaser tráiler de Episodio 1 era el cine. La misma tarde y años antes de la aparición de los sitios webs para compartir vídeo [...] un puñado de fans de Star Wars grabó, digitalizó, subió y compartió el teaser a través de la web. Lucasfilm [...] tardó cuatro días en postear su propia versión [...]. Cuando finalmente lo hizo, cuatrocientos cincuenta fans de Star Wars por segundo intentaban descargarse el tráiler [...] alrededor de doscientos mil en cuarenta y ocho horas, una estimación de un millón y medio de descargas en la primera semana, llegando a un total de tres millones y medio de descargas (2008: 147-148 / TdA).

En sus comienzos, la página de Apple alojaba únicamente algunos tráilers de estudios que se habían arriesgado a dar el salto a la web ${ }^{4}$. Sin embargo, tras el éxito de esta campaña, los

\footnotetext{
${ }^{3}$ En el enlace http://trailers.apple.com (consultado: 01/11/2011).

4 "¿Cómo llegaron los tráilers de cine a la web de Apple?", en http://www.applesfera.com/apple/comollegaron-los-trailers-de-cine-a-la-web-de-apple (consultado: 01/11/2011).
} 
estudios empiezan a enviar una gran cantidad de tráilers a Apple y el uso de tráilers online comienza a extenderse y generalizarse al resto de producciones cinematográficas ${ }^{5}$.

La promoción cinematográfica a través de internet ha demostrado ser tan eficiente que, actualmente, se presta una especial atención al número de espectadores que visionan o descargan el tráiler de la web. De este modo, el estreno del tráiler llega a convertirse en un evento igual de importante que el estreno cinematográfico. El estreno online del tráiler de Indiana Jones y el reino de la calavera de cristal (Indiana Jones and the Kingdom of the Crystal Skull, Spielberg, 2008) fue visto por más de 200 millones de personas en la primera semana (Bowles, 2008); y el de Piratas del Caribe. En el fin del mundo (Pirates of the Caribbean: At World's End, Verbinski, 2007), por más de trescientos setenta y cinco millones de personas en sesenta y dos países, también en su primera semana (Giardina, 2007).

El tráiler online ha modificado, además, la duración de la propia campaña promocional de la película. Con internet, el tráiler no desaparece tras la explotación comercial inicial de la película sino que continúa disponible en la red. De esta forma, al contrario que la publicidad impresa o la publicidad televisiva, limitadas por el tiempo y el espacio, la publicidad en internet permite que la campaña de una película se encuentre continuamente presente para el espectador (VVAA, 2006c: 10). Como explica Stuart Williams, director de marketing de Columbia TriStar Films UK, a propósito de la campaña de promoción de Spider-Man 2 (Raimi, 2004): "El beneficio de lo online es que puede crearse un recurso que sea accesible a las personas a cualquier hora" $(\mathrm{TdA})^{6}$.

Internet se convierte, en definitiva, en una especie de archivo de tráilers (Johnston, 2009: 161) y el ciclo de vida del tráiler se asimila al de la película:

El ciclo de vida del producto película comienza en el proceso de producción y termina cuando la explotación comercial ha recorrido todas las ventanas de exhibición conocidas. Las formas de exhibición domésticas permiten el visionado de una película en cualquier ocasión [...]. En este sentido, el ciclo de vida del producto podría ampliarse a la permanencia en el mercado, siendo definitivo cuando el producto quede descatalogado. La descatalogación no supone la desaparición de la película en el nuevo contexto audiovisual, ya que gracias a medios como Internet y el intercambio de archivos, es posible recuperar películas ya olvidadas por el mercado [...]. Estas películas vuelven a ser objeto de transacciones (no comerciales) entre diferentes usuarios de la red (Izquierdo, 2010: 55-56).

De este modo, hoy, el tráiler, al igual que la película, puede ser revisionado por el espectador en cualquier momento:

Originalmente, el tráiler se exhibía únicamente en el cine, con lo que no existia ninguna posibilidad de archivarlo o re-estrenarlo. Formaba parte del espectáculo cinematográfico y no había otro lugar en el que se pudiera consumir [...]. El tráiler se veía en el mismo espacio en el que se proponía atraer de vuelta a la audiencia [...]. Cuando el tráiler se convierte en online [...] se consume fuera del espacio cinematográfico y no necesariamente con el objetivo de anunciar una película (Williams, 2009: 1-2 / TdA).

\footnotetext{
${ }^{5}$ Ibídem

${ }^{6}$ Véase en http://www.dynamiclogic.com/case study spiderman.pdf (consultado: 01/08/2011).
} 
Esto plantea una nueva dimensión: el tráiler puede entenderse como un subproducto de la película de próximo estreno y, al mismo tiempo, como un "recordatorio fetiche" para aquellos espectadores que ya han visto la película (Zanger, 1998: 208 / TdA). Ante este nuevo panorama, y como concluye Kernan, se diluyen las fronteras entre el marketing de cine y el revisionismo cinematográfico (2004: 217).

\subsection{El espectador distribuye el tráiler}

La aparición de la web 2.0 supone un cambio de paradigma en la comunicación en internet y se beneficia de toda una serie de nuevos formatos y herramientas de comunicación (blogs, redes sociales, podcasts, wikis, sitios contenedores de vídeo y fotos, etc....) en la que conceptos como la interactividad, la inmediatez y la comunicación interpersonal juegan un papel fundamental (Lozano y Hermida, 2010: 2). Xavier Ribes define la web 2.0 de la siguiente forma:

Podemos considerar como Web 2.0 todas aquellas utilidades y servicios de Internet que se sustentan en una base de datos, la cual puede ser modificada por los usuarios del servicio, ya sea en su contenido (añadiendo, cambiando o borrando información o asociando metadatos a la información existente), bien en la forma de presentarlos o en contenido y forma simultáneamente (2007).

El concepto 2.0 propone, en definitiva, un renovado escenario, una nueva forma de comunicarse, relacionarse, experimentar y compartir (Cortés, 2009: 13). Esta redefinición de la red transforma la estrategia comunicacional unidireccional y obsoleta que existía entre el emisor y el receptor en internet (Lozano y Hermida, 2010: 2).

\footnotetext{
Los receptores de los medios de comunicación, los compradores, los consumidores, los trabajadores, los ciudadanos, los contribuyentes... se encuentran en sus manos la capacidad de hacerse oír, proporcionar contenidos, innovar, crear valor y poder ser escuchado en un espacio virtual interconectado que se extiende por el mundo (De Salas, 2009: 77).
}

Este nuevo escenario modifica nuevamente la campaña publicitaria de la película y el modo en que la industria cinematográfica se dirige al espectador. El tráiler se transforma en un contenido que el propio consumidor puede valorar y compartir (a través de marcadores sociales como "Tweet" o "Me gusta", de Twitter y Facebook respectivamente) con sus amigos en la red. Como indica Kerrigan, antes del desarrollo de las redes sociales, resultaba difícil para un consumidor que no tuviese conocimientos tecnológicos avanzados ver y compartir tráilers en espacios online (2009: 200). Sin embargo, gracias a la aparición de la web 2.0, el espectador cuenta, por vez primera, con toda una variedad de espacios personales en los que ver, valorar y compartir sus tráilers favoritos, contribuyendo de este modo a la propagación del mensaje comercial. 
Facebook o Twitter permiten a sus usuarios compartir vídeos con sus amigos. Tumblr o cualquier otra plataforma de blogging o microblogging posibilita publicar el tráiler como post. YouTube permite a sus usuarios crear canales personales en los que subir sus vídeos preferidos, etc. El consumidor, se transforma, de este modo, en el mejor embajador de la película, involucrándose activamente en la distribución del tráiler en la red, contribuyendo al marketing viral online y generando word of mouth -positivo o negativo- acerca del filme.

En términos generales, puede decirse que, actualmente, el consumo de tráilers en internet se organiza en dos momentos. En un primer momento, el espectador visiona el tráiler, pudiendo repetir la reproducción las veces que quiera. $Y$ en un segundo, el receptor se transforma en emisor, compartiendo el tráiler con sus amigos y contribuyendo a su distribución en la red. Aun así, no hay que olvidar que el emisor original del tráiler es casi siempre la productora o distribuidora de la película. Se trata de un emisor institucional, único y oficial. El rol que juega el receptor es el de re-emitir el mensaje comercial y distribuirlo en la red. En algunos casos, el propio espectador o fan se adelanta al estreno oficial online subiendo una grabación casera del tráiler tomada durante su proyección en cines u otros eventos (como el Comic-Con de San Diego), de forma similar a lo que ocurrió también con el tráiler de Episodio 1 antes de su estreno en internet.

\subsection{El espectador navega por el tráiler}

En los últimos años se está otorgando cada vez más importancia al receptor en el proceso de comunicación y la industria cinematográfica está ideando constantemente nuevos formatos publicitarios que supongan un rol más activo por parte del espectador. De este modo, de un lado, se introducen nuevas estrategias publicitarias más interactivas y creativas tales como advergames, utilidades para la creación de avatars, Live Experiences en Facebook, experiencias a través de tecnología BD-Live, apps (aplicaciones) para iPhone e iPad, estrategias basadas en Realidad Aumentada, etc (Lozano y Hermida, 2010: 16-17). Y de otro, los formatos clásicos se ven obligados a renovarse o, incluso, a fusionarse con otros para poder mantenerse actualizados (2010: 17). Así surge, por ejemplo, el motion poster que no es más que una hibridación del tráiler y el cartel; o la web promocional, que evoluciona hasta convertirse en algo más que un portal de información, confundiéndose en ocasiones con el tráiler (construyéndose a través de escenas de la película) o el videojuego (el usuario debe jugar con la propia web para conseguir la información que está buscando) (2010: 17).

En lo que respecta al tráiler, se observa, en algunos casos, una transformación importante en su modo de reproducción. Actualmente, el espectador es ya capaz de navegar por el tráiler como si se tratase de una web. Este tipo de tráiler se conoce como interactive trailer o i-Trailer (tráiler interactivo). Estos tráilers interactivos son idénticos al tráiler original de la película con la diferencia de que al espectador se le permite navegar y explorar contenidos adicionales que va descubriendo conforme avanza el visionado del tráiler. Un ejemplo es el 
tráiler interactivo de Sed de venganza (Faster, Tillman Jr., 2010) ${ }^{7}$. Este tráiler (ver imagen no 1) comienza con una breve introducción (imagen 1) en la que el actor principal explica al espectador el funcionamiento del tráiler interactivo: "Puedes hacer click en cualquier lugar de la pantalla en cualquier momento para obtener todas la información que necesitas conocer sobre Sed de venganza" (TdA). Luego, se inicia la reproducción del tráiler y el cursor del ratón va anunciando, a través de tooltips (imágenes 2 y 4), diferentes contenidos adicionales que el espectador puede ir guardando (con solo hacer click) para su posterior visionado o consulta. Por lo general, se trata de material promocional extra como información sobre la película, fichas de personajes, fotos de rodaje, entrevistas al equipo artístico o técnico (imagen 3), making of o incluso algunas escenas extraídas del filme. Estos contenidos se guardan en un menú anexo a la propia ventana de reproducción del tráiler y el espectador puede acceder a ellos en cualquier momento, pausando el tráiler y navegando a través de los diferentes ítems. Una vez terminado el visionado o consulta de estos contenidos, el espectador puede volver a la reproducción del tráiler en el instante en que lo había dejado.

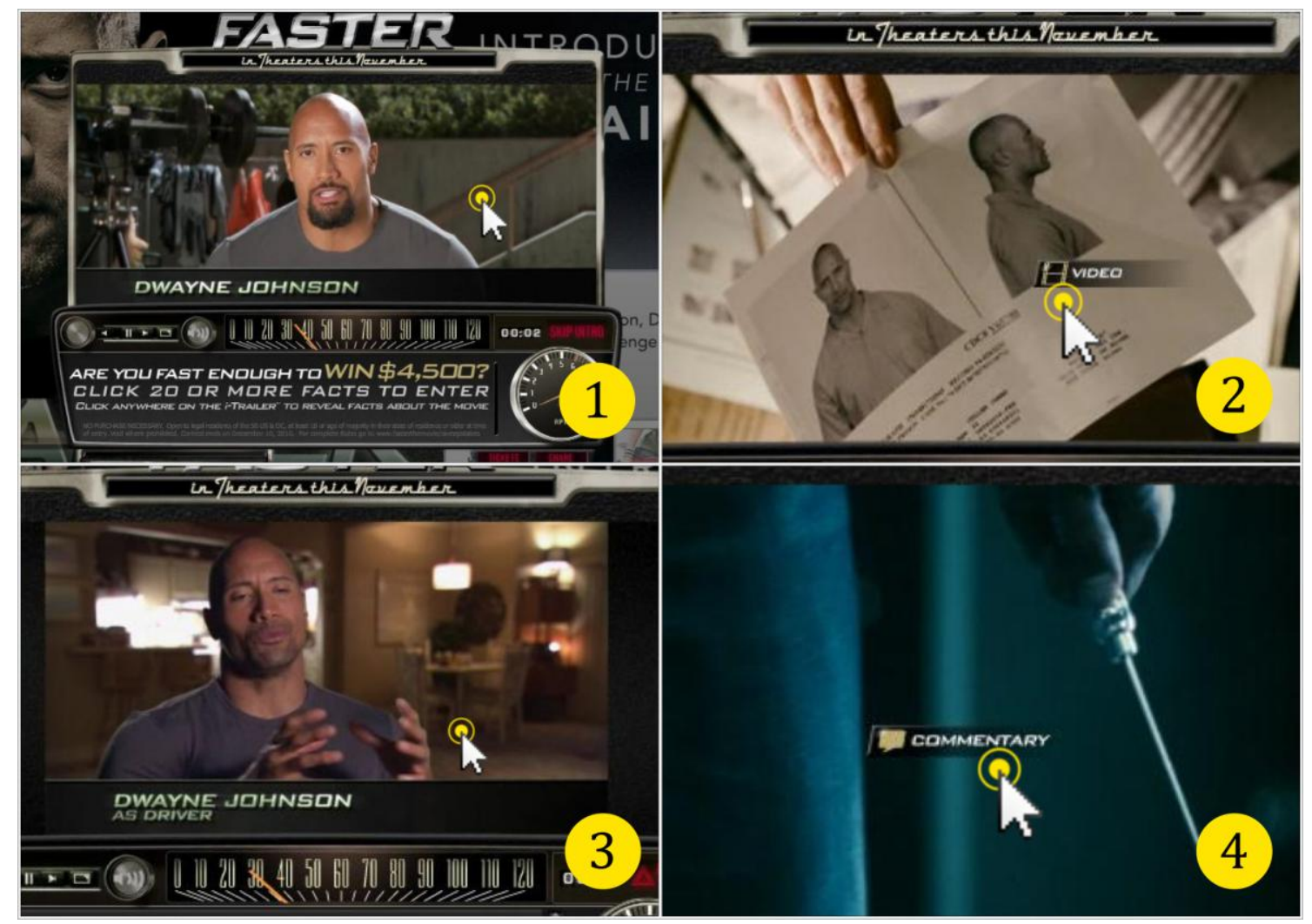

Imagen 1. Tráiler interactivo de Sed de venganza (Fuente: elaboración propia)

Puede decirse que el tráiler interactivo funciona, en última instancia, como un microsite a través del cual el espectador puede navegar y acceder a material extra que, hasta entonces se encontraba disponible únicamente en la web promocional de la película. Es decir, el espectador no solo continúa controlando la reproducción sino que, además, y como valor

\footnotetext{
${ }^{7}$ Véase en http://www.i-trailers.com/iTrailers/Faster/index.html (consultado: 01/11/2011).
} 
añadido, puede pausar el visionado en cualquier momento para explorar y descubrir toda una serie de contenidos promocionales adicionales. Según Masiclat y Klein,

más allá de los propósitos tradicionales de la promoción [...], la promoción online pretende, generalmente, satisfacer una necesidad adicional del usuario por implicarse con los personajes, la trama o los creadores de la película, y estos objetivos se están trasladando a los nuevos medios de comunicación (2006: 225 / TdA).

Se trata, en definitiva, de generar un discurso digital con el espectador de tal forma que el consumo del material publicitario de la película se transforme en una experiencia interactiva que va más allá de la propia reproducción.

En ocasiones, la experiencia que propone el tráiler interactivo es similar a la de un advergame. El espectador accede por su cuenta a la información promocional del filme y "juega" con ella, transformando el mensaje comercial en una actividad lúdica original e innovadora (Lozano y Hermida, 2010: 18). En el tráiler interactivo de Fast \& Furious 5 (Fast Five, Lin, 2011) ${ }^{8}$, el espectador debe desbloquear una serie de elementos clave que le permitan el acceso a nuevos contenidos al final del tráiler. En el caso de Megamind (McGrath, 2010), se establece una cuenta atrás antes de comenzar el tráiler ("3, 2, 1, GO!"), como si el espectador estuviese a punto de comenzar un videojuego ${ }^{9}$.

Estos ejemplos son una prueba de los esfuerzos de la industria cinematográfica por crear nuevas experiencias interactivas para el espectador. Sin embargo, en la mayoría de los casos, la reproducción de los materiales extra implica un visionado independiente al del propio tráiler, dividiendo la reproducción en dos discursos diferentes que no parecen integrarse de forma adecuada. En este sentido, resulta preciso señalar que algunas promos ${ }^{10}$ interactivas que se están realizando en el ámbito de las series de televisión resultan mucho más atractivas al ser capaces de combinar de forma coherente el discurso de la promo con el del material extra que va apareciendo en pantalla. Un ejemplo es la promo de la tercera temporada de la serie británica Skins (Elsley y Brittain, Channel 4, 2007-) ${ }^{11}$.

Esta promo presenta, durante una secuencia en un bar, a los diversos personajes que participarán en la nueva temporada (imagen no 2). Conforme cada uno de los personajes va apareciendo en pantalla, su nombre se va añadiendo en la parte superior de la ventana de reproducción a modo de submenú. Cuando el espectador hace click en sus nombres (imagen 3 para el personaje de Cook y 4 para el de Pandora) la promo se detiene y encadena, mediante un efecto de transición, la reproducción de un pequeño fragmento en el que el correspondiente personaje ofrece una pequeña descripción en voz en off sobre su forma de ser, al mismo tiempo que se muestran diversas escenas interactuando con sus amigos en el

\footnotetext{
${ }^{8}$ Véase en http://www.fastfivemovie.com/itrailer/ (consultado: 01/11/2011).

${ }^{9}$ Véase en http://www.theppc.com/blog/2010/12/mega-trailer/ (consultado: 01/11/2011).

${ }^{10}$ En este sentido, conviene precisar que el término promo se utiliza para referirse a un anuncio de un programa televisivo.

${ }^{11}$ Véase en http://www.e4.com/skins/interactive-trailer.html (consultado: 01/11/2011).
} 
bar (imagen 1 para Cook y 2 para Pandora). Cuando este segmento llega a su fin, la promo reanuda su reproducción.
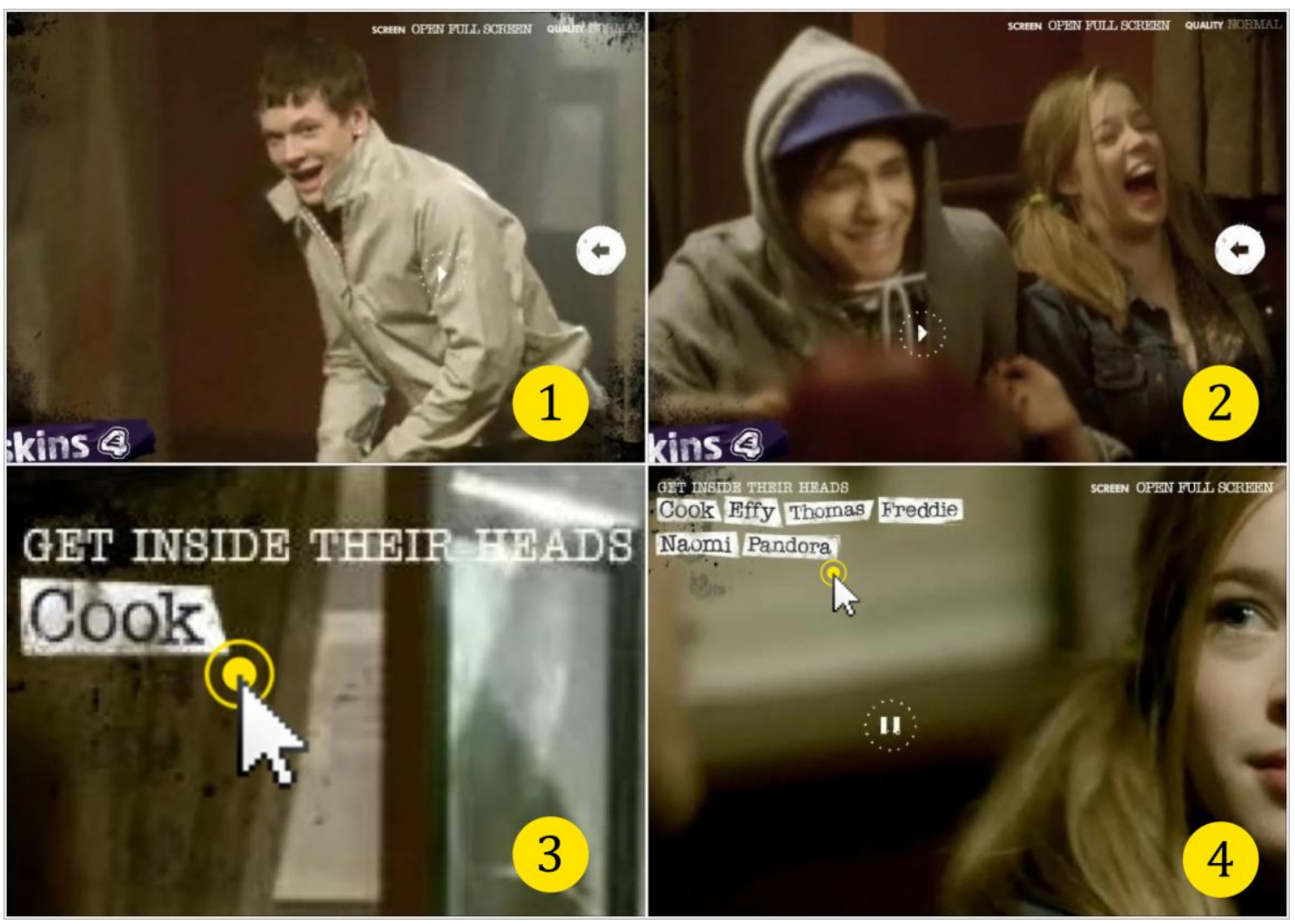

Imagen 2. Promo de la tercera temporada de Skins (Fuente: elaboración propia)

El fragmento de vídeo extra funciona, por tanto, como una ficha detallada de cada personaje. Gracias a la promo interactiva el espectador puede adentrarse en la mente de los diferentes personajes conforme estos van apareciendo en escena ${ }^{12}$. Los fragmentos extras ofrecen un punto de vista particular y diferente a la perspectiva general que se muestra en la promo y sirven para profundizar mejor en la psicología de cada personaje. En este caso, al contrario que en los casos presentados de tráiler interactivo, la aparición del contenido extra se encuentra perfectamente integrado con el discurso de la promo.

\subsection{El espectador crea el tráiler}

Con el tráiler interactivo el espectador puede navegar y explorar contenidos adicionales en el tráiler. No obstante, este tipo de tráiler se sigue presentando como una experiencia interactiva a medias, en la que las acciones del espectador se encuentran bastante limitadas (solo se puede hacer click cuando el tootip aparece en pantalla) y en la que el grado de participación se limita únicamente al descubrimiento y visionado de material promocional extra. Como indica Juan Salvador Victoria: "Cuando hablamos de interactividad, nos

${ }^{12}$ En la parte superior de la promo interactiva, donde aparecen los nombres de los personajes, también aparece la frase: "Introdúcete en sus cabezas" (TdA). 
referimos a un proceso que permite comprometer a la audiencia en la comunicación; los usuarios no son sólo receptores de mensajes, sino creadores activos de sus mensajes" (2005: 295). En los últimos años, han surgido algunos ejemplos que apuntan a la aparición de un nuevo tipo de tráiler que concede un rol más activo al consumidor y en los que la experiencia interactiva es aun mayor.

En estos tráilers, la participación del consumidor no se limita a la distribución o interactuación con los contenidos sino que contribuye, además, a la construcción del propio tráiler, transformándose, por tanto en prosumer o prosumidor del mensaje comercial. El término prosumer fue acuñado por Toffler en su obra La tercera ola, haciendo referencia a un nuevo agente de la aldea global que no se limita a su función de consumidor sino que puede aportar también otros bienes o servicios (1980: 261-263). En este sentido,

\begin{abstract}
el prosumidor hace referencia a una nueva tipología de consumidor que se aleja de la actitud conformista del cliente tradicional [...] son personas con capacidad de liderazgo y persuasión que viven de una forma activa y que desean propagar su mensaje porque lo sienten como propio (Ramos, 2008: 48).
\end{abstract}

Un ejemplo de todo esto es el Trailer Painter ${ }^{13}$ concebido para la campaña publicitaria de la película Sucker Punch (Snyder, 2011) (ver imagen no 3). A través de una herramienta online disponible en la misma web, el espectador puede acceder a los diferentes fotogramas que componen el tráiler para redibujarlos o colorearlos digitalmente, confiriendo un estilo de cómic en consonancia con la estética del filme. Para los usuarios más avanzados existe también la posibilidad de descargar la imagen y modificarla mediante programas de diseño de escritorio como Photoshop o Illustrator.

El objetivo final es crear una especie de wiki-tráiler o tráiler colectivo construido por diferentes usuarios siguiendo la estrategia del User Generated Content (generalmente vinculado a la figura del prosumidor). Los participantes también pueden explorar los diseños de otros usuarios y votarlos. Al finalizar la experiencia, Warner Bros. lanzó dos tráilers: uno como resultado de los fotogramas seleccionados por un jurado oficial; y otro, compuesto por los fotogramas más votados.

Una vez más, conviene precisar que este tipo de acciones se encuentran mucho más extendidas en la promoción de series de televisión. En los últimos años, la industria televisiva está apostando fuerte por la comunicación publicitaria 2.0 y se está adelantando, en muchos aspectos, a la industria del cine. Teniendo en cuenta el grado de influencia de estos dos medios, resulta importante estudiar los nuevos tipos de promo que están surgiendo en el panorama televisivo y que podrían extenderse, más adelante, a la industria cinematográfica.

\footnotetext{
${ }^{13}$ Véase en http://suckerpunchmovie.warnerbros.com/painter (consultado: 01/11/2011).
} 


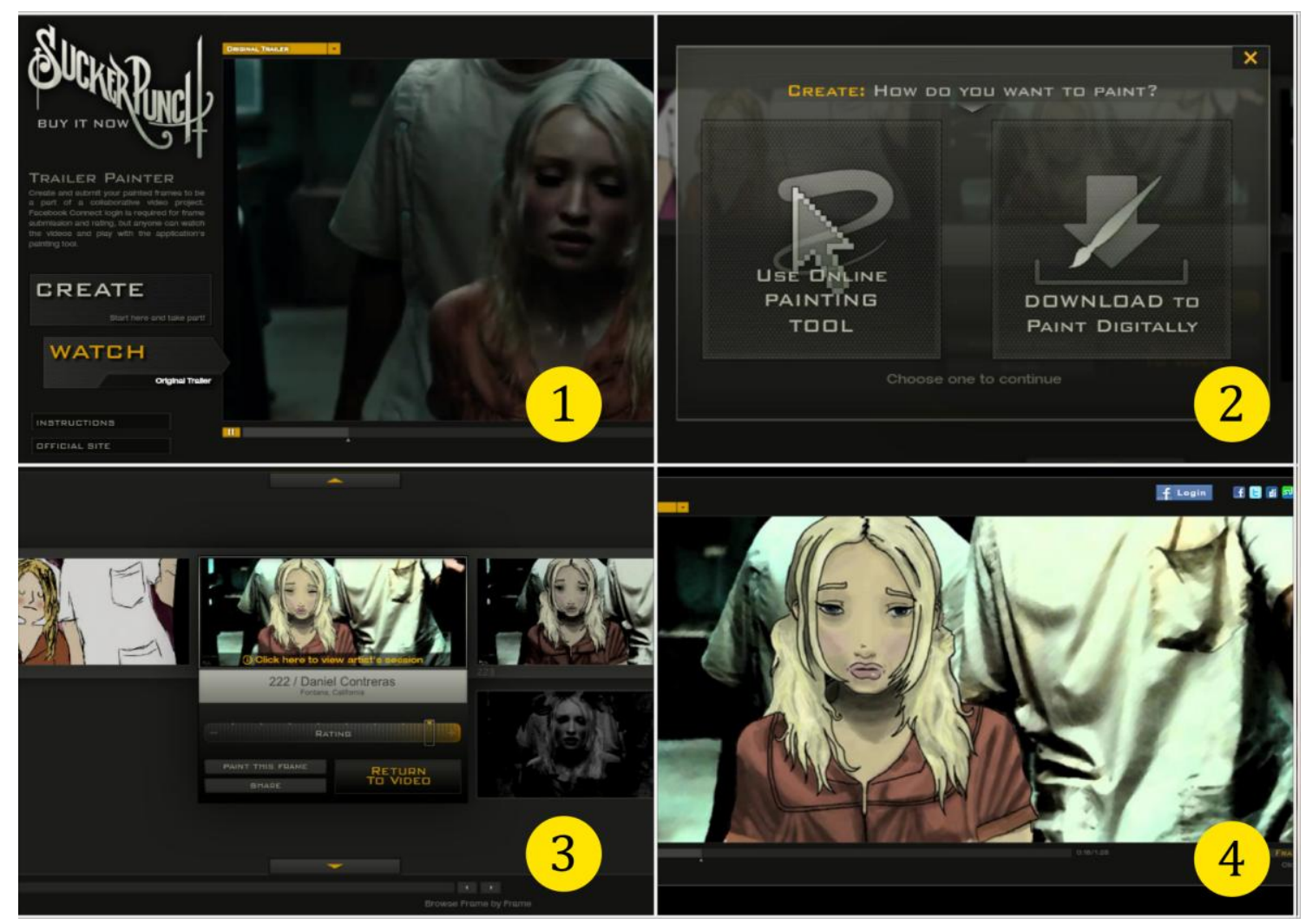

Imagen 3. Trailer Painter de Sucker Punch (Fuente: elaboración propia)

Así, de un lado, la cadena británica BBC ofrece en la web promocional de sus series Doctor Who (BBC, 2005-) y The Sarah Jane Adventures (Davies, CBBC, 2007-) un trailer maker ${ }^{14}$ que, a través de un avanzado software de edición online, permite al espectador construir la promo de su serie favorita. El espectador puede elegir entre diversas escenas de la serie, efectos sonoros, temas musicales, títulos y gráficos e, incluso, efectos especiales. $Y$ de otro, algunas series norteamericanas han transformado la creación del tráiler en un concurso. El trailer maker que se lanzó para promocionar la octava temporada de Smallville ${ }^{15}$ (Gough y Millar, The cW, 2000-2011) premiaba a los concursantes que realizasen el mejor tráiler con un teléfono móvil Nokia 5310 Xpress Music y una pantalla plana LG. En el caso de Perdidos (Lost, Abrams, ABC, 2004-2010), los espectadores tenían que realizar una promo (con sus propios medios o recurriendo al trailer maker que se encontraba en la página oficial de la serie) para anunciar la season finale (Ramos y Lozano, 2011: 429).

Existen también algunos ejemplos de trailer makers para películas de cine. Sin embargo, en estos casos, estas herramientas se han desarrollado con un propósito educativo y no publicitario. La Film Education ${ }^{16}$ promueve la educación del cine en las escuelas británicas y suministra al maestro un completo programa sobre el estudio y construcción de un tráiler

14 Véase en http://www.bbc.co.uk/doctorwho/trailermaker y http://www.bbc.co.uk/cbbc/sja/ funandgames/trailermaker (consultado: 01/08/2011).

${ }^{15}$ Véase en http://smallvilletrailermaker.warnerbros.com (consultado: 01/08/2011).

${ }^{16}$ En el enlace http://www. filmeducation.org> (consultado: 01/11/2011). 
(Teaching Trailers ${ }^{17}$ ). Entre las actividades que propone, destacan dos trailer makers para las películas de Thor $^{18}$ (Branagh, 2011) y Cars $2^{19}$ (Lasseter y Lewis, 2011) que funcionan de forma muy similar a lo visto en Doctor Who o Smallville.

Con estas experiencias se demuestra, una vez más, la importancia que el prosumidor está adquiriendo en el proceso de comunicación publicitaria. Se trata, en definitiva, de crear entretenimiento en torno a la marca (advertainment) y, al mismo tiempo, generar una conversación directa con el consumidor, haciéndole partícipe de una especie de comunidad en torno al producto o servicio: "Conseguir que se comprometan contigo, que vivan una experiencia con el consumidor es el objetivo para conseguir pasar de clientes a seguidores, a 'fans' de tu marca" (Cortés, 2009: 16). Es decir, la mejor forma de destacar es construyendo una experiencia de consumo, una especie de comunidad que permita convertir al prosumidor en un seguidor incondicional que consume $y$, al mismo tiempo, produce contenidos para una determinada película (Lozano y Hermida, 2010: 18).

Aunque, a lo largo de la historia, la industria del entretenimiento ha confiado siempre en el contenido de las imágenes del tráiler para atraer espectadores a la sala de cine, hoy la situación parece estar cambiando. Ya no se trata únicamente del contenido sino, sobre todo, de la forma en que este contenido se presenta en internet. En otras palabras, ya no es cuestión solo de presentar el contenido de una película en imágenes, sino de presentarlo y ofrecerlo de forma atractiva, original y diferente. El tráiler no debe conformarse únicamente como una ventana hacia la película, sino que debe transformarse en una experiencia para el espectador que combine, al mismo tiempo, entretenimiento e interactividad.

\section{Conclusiones}

La primera conclusión que se infiere tras este trabajo es que el tráiler se caracteriza por una gran versatilidad para adaptarse a diferentes soportes de visionado. Como indica Johnston, se trata de "uno de los pocos textos visuales que existe en múltiples pantallas tecnológicas" (2008: 145 / TdA). Como resultado de la diversificación de soportes y de su difusión a través de otros canales o medios de comunicación, el espacio de consumo del tráiler así como el tipo de consumo se ha transformado con el paso de los años. En un primer momento, el consumo del tráiler se realiza en la sala de cine, durante el espectáculo cinematográfico. Se trata de un consumo colectivo que tiene lugar en el espacio destinado a la exhibición cinematográfica. En un segundo, al consumo cinematográfico se añade el consumo doméstico, gracias a la aparición de la televisión, el vídeo doméstico y, sobre todo, la aparición de internet. En esta ocasión, se trata de un consumo que puede ser tanto colectivo como individual y que también tiene lugar en un espacio concreto, ya sea el propio hogar del

\footnotetext{
${ }^{17}$ En el enlace http://www.filmeducation.org/teachingtrailers > (consultado: 01/11/2011).

${ }^{18}$ Véase en http://www.filmeducation.org/thor/make the cut> (consultado: 01/11/2011).

${ }^{19}$ Véase en http://www.filmeducation.org/teachingtrailers/primary/make a trailer> (consultado: 01/11/2011).
} 
receptor u otro lugar que cuente con el sistema de reproducción adecuado. $Y$ en un tercero, el tráiler se consume as you go. Esto es, el espacio de consumo se independiza de los reproductores domésticos y los ordenadores de sobremesa y se extiende a cualquier lugar de la esfera pública gracias a los nuevos dispositivos de reproducción portátiles. De este modo, mientras que el consumo de tráilers supone, en su origen, una experiencia colectiva ubicada en la sala de cine, hoy en día se tiende más hacia una individualización del consumo que no requiere de un espacio fijo ya que los contenidos se encuentran constantemente disponibles on demand a través de internet.

En segundo lugar, la aparición de internet introduce, como se ha visto, cuatro novedades importantes en el consumo de tráilers. Cada una de estas novedades implica una mayor participación del receptor/espectador en el proceso comunicativo. De este modo, el espectador comienza controlando el acceso al tráiler para posteriormente participar en la distribución del mensaje publicitario (emisor 2.0) o interactuar con los contenidos promocionales hasta convertirse, finalmente, en el propio productor del mensaje publicitario de la película, participando en la creación del tráiler.

Por último, conviene destacar que esta evolución del tráiler y su constante transformación para ofrecer una experiencia más interactiva y atractiva al espectador refleja a la perfección los esfuerzos de la industria cinematográfica y publicitaria por adaptarse al entorno comunicativo actual. Aunque por el momento son pocos los ejemplos que pueden documentarse de tráilers en los que se requiere la participación del espectador, se infiere que, en los próximos años, estas prácticas comenzarán a proliferar como resultado de la evolución de los nuevos modelos comunicativos inspirados en el paradigma 2.0. Igualmente, el proceso de visionado del tráiler podrá convertirse en una experiencia completamente personalizada en la que el espectador controlará innumerables variables que permitirán la mejora de las condiciones de visionado. Actualmente, el espectador puede elegir la calidad de visualización o descarga del tráiler e, incluso, la superposición de subtítulos que traducen el audio original, haciendo el tráiler extensible a cualquier parte del mundo, con la eliminación de las barreras idiomáticas. Este nuevo panorama de consumo y de recepción de tráilers irá creciendo exponencialmente con el paso de los años y las nuevas características y opciones de personalización que, a día de hoy, pueden parecer novedosas se convertirán en estándares en el proceso de visualización de tráilers y se incorporarán otras nuevas que transformarán definitivamente la experiencia que ofrece el tráiler.

\section{REFERENCIAS BIBLIOGRÁFICAS}

Amorós, Anna y FonTÁn, Ma Olga (2010): "Soportes y formatos en la nueva producción audiovisual. Evolución. Características. Tendencias", en II Congreso Internacional AE-IC Málaga 2010: Comunicación y desarrollo en la era digital, en http://www.ae-ic.org/malaga2010/upload/ok/210.pdf (consultado: 01/11/2011). 
BowLES, Scott (2008): "Here come Harrison and 'Indiana'; Trailer arrives Thursday; film opens May 22", en USA Today, 13 de febrero.

CNC (2000): Étude sur les titres, affiches et bandes-annonces de films. París, QualiQuanti.

CORTÉS, Marc (2009) "Bienvenido al nuevo marketing", en Sanagustín, E. (Dir.), Del 1.0 al 2.0: Claves para entender el nuevo marketing. Bubok Publishing, pp. 6-23.

De SALAS, Ma Isabel (2009): "La publicidad en las redes sociales", en Icono 14, no 15, pp. 75-84, en: http://www.icono14.net/index.php/monografico/ publicidad-redes-sociales. (consultado: 01/11/2011).

GIARDINA, Carolyn (2007): "World welcomes 'Pirates' trailer", en The Hollywood Reporter, 2 de abril.

HAYES, Dade y BING, Jonathan (2004): "Tiranny of the trailer", en Variety, semana del 23 de febrero al 29 de febrero, p. 1.

Hediger, Vinzenz (2002): "Cartografia degli affetti. A proposito delle marche di genere nei trailer cinematografici", en Comunicazioni sociali, vol. 24, no 2, pp. 202-211.

IzQuieRdo, Jessica (2010): El cine digital. La distribución y exhibición españolas ante el reto tecnológico. Sevilla, Ediciones Ciencias Sociales.

JOHNSTON, Keith (2008): "The coolest way to watch movie trailers in the world", en Convergence, vol. XIV, no 2, pp. 145-160.

------- (2009): Coming Soon. Film Trailers and the Selling of Hollywood Technology. Carolina del Norte, McFarland.

KERNAN, Lisa, (2004): Coming attractions : reading American movie trailers. Austin, University of Texas Press.

LOZANO, Javier y HERMIDA, Alberto (2010): "La metamorfosis publicitaria digital. Nuevas estrategias de promoción en la industria del cine y la televisión a través de internet", en las actas del II Congreso Internacional AE-IC Málaga 2010: Comunicación y desarrollo en la era digital, en http://www.aeic.org/malaga2010/upload/ok/254.pdf (consultado: 01/08/2011).

MASiclat, Steven y KLEIN, Robert A. (2006) "New Media Promotion", en Eastman, S.T., Ferguson, D.A. y Klein, R.A., Media Promotion Marketing for Broadcasting, Cable and the Internet. Burlington, Focal Press, pp. 223-245.

RAmos, Marina (2008): "Nuevos escenarios de la comunicación y la opinión pública", en VVAA, Nuevos escenarios de la comunicación y la opinión pública, vol. 1, pp. $45-52$. 
Ramos, Marina y LozANo, Javier (2011): "Promoting Lost. New Strategies and Tools of Commercial Communication", en Pérez, Miguel A., Previously on: estudios interdisciplinarios sobre la ficción televisiva en la Tercera Edad de Oro de la Televisión. Sevilla, Biblioteca de la Facultad de Comunicación, pp. 421-432, en: http://fama2.us.es/fco/frame/ (consultado: 01/11/2011).

Ribes, Xavier (2007): "La Web 2.0. El valor de los metadatos y de la inteligencia colectiva", en Telos, n073, en: http://sociedadinformacion.fundacion. telefonica.com/telos/articuloperspectiva.asp@idarticulo=2\&rev=73.htm (consultado: 01/11/2011).

Toffler, Alvin (1980): La tercera ola. Barcelona, Plaza \& Janés.

THE ANDREW J. KUEHN JR. FOUNDATION (2006): Coming attractions. The history of movie trailers. Los Angeles.

VICTORIA, Juan Salvador (2005): Reestructuras del sistema publicitario. Barcelona, Ariel.

VVAA (2006c): "Promoting the Media: Scope and Goals", en Eastman, S.T., Ferguson, D.A. y Klein, R.A.: Media Promotion Marketing for Broadcasting, Cable and the Internet. Burlington, Focal Press, pp. 1-29.

WilliamS, Kathleen (2009): "Re-reading the history of the trailer: The production and consumption of 'recut' trailers", en: http://unsw.academia.edu/ KathleenWilliams/Papers/469705/Re-reading the history of the trailer The production and consumption of recut trailers (consultado: 01/11/2011).

ZANGER, Anat (1998): "Next on your screen: the double identity of the trailer", en Semiotica, 120-1/2, pp. 207-230.

ZuFryDEN, Fred (2000): "New Film Website Promotion and Box-Office Performance", en Journal of Advertising Research, Enero-Abril, pp. 55-64.

[Recibido: 28 de mayo de 2011. Aceptado: 12 de marzo de 2012]. 